\title{
Antiplatelet and anticoagulation strategies for left ventricular assist devices
}

\author{
Renzo Y. Loyaga-Rendon ${ }^{1}$, Toshinobu Kazui ${ }^{2}$, Deepak Acharya ${ }^{3}$ \\ ${ }^{1}$ Spectrum Health, Grand Rapids, MI, USA; ${ }^{2}$ Division of Cardiothoracic Surgery, University of Arizona, Tucson, AZ, USA; ${ }^{3}$ Division of \\ Cardiovascular Diseases, University of Arizona, Tucson, AZ, USA \\ Contributions: (I) Conception and design: All authors; (II) Administrative support: None; (III) Provision of study materials or patients: All authors; \\ (IV) Collection and assembly of data: All authors; (V) Data analysis and interpretation: All authors; (VI) Manuscript writing: All authors; (VII) Final \\ approval of manuscript: All authors. \\ Correspondence to: Deepak Acharya, MD, MSPH. Division of Cardiovascular Diseases, Sarver Heart Center, University of Arizona, 1501 North \\ Campbell Ave, Tucson, AZ 85719, USA. Email: dacharya@shc.arizona.edu.
}

\begin{abstract}
Left ventricular assist devices (LVAD) have revolutionized the management of advanced heart failure. However, complications rates remain high, among which hemorrhagic and thrombotic complications are the most important. Antiplatelet and anticoagulation strategies form a cornerstone of LVAD management and may directly affect LVAD complications. Concurrently, LVAD complications influence anticoagulation and anticoagulation management. A thorough understanding of device, patient, and management, including anticoagulation and antiplatelet therapies, are important in optimizing LVAD outcomes. This article provides a comprehensive state of the art review of issues related to antiplatelet and anticoagulation management in LVADs. We start with a historical overview, the epidemiology and pathophysiology of bleeding and thrombotic complications in LVADs. We then discuss platelet and anticoagulation biology followed by considerations prior to, during, and after LVAD implantation. This is followed by discussion of anticoagulation and the management of thrombotic and hemorrhagic complications. Specific problems, including management of heparin-induced thrombocytopenia, anticoagulant reversal, novel oral anticoagulants, artificial heart valves, and noncardiac surgeries are covered in detail.
\end{abstract}

Keywords: Heart failure (HF); left ventricular assist devices (LVAD); anticoagulation; antiplatelet

Submitted Jun 21, 2020. Accepted for publication Jul 31, 2020.

doi: 10.21037/atm-20-4849

View this article at: http://dx.doi.org/10.21037/atm-20-4849

\section{Introduction}

"When the blood leaves its contact with normal intima and endocardial surfaces and flows over a foreign surface of any kind, it undergoes abnormal changes, and the longer this contact continues, the more severe become the changes." These were reflections of Dr. Michael DeBakey in 1971 as he described the first left ventricular assist device (LVAD) implants in the 1960s. He concluded "Mechanical assistance for long-term support or possible total replacement of the biologic heart therefore remains unachieved insofar as a satisfactory blood interface is concerned. The blood interface is perhaps the most critical problem yet to be solved in the development of an artificial heart." (1). Since that time, advances in VAD technology now allow patients to live a near-normal life at home for years on device therapy. However, issues of biocompatibility, hemostasis and thrombosis remain central in VAD design and patient management.

\section{Historical overview}

The advent of cardiopulmonary bypass (CPB) in the 1950s paved the way for mechanical circulatory support (MCS) and artificial heart programs in the 1960s. Early LVADs were large, paracorporeal, and required patients to remain 
in the hospital until transplant. A variety of antithrombotic regimens were tested.

A major change in the LVAD landscape came with the REMATCH trial where patients with advanced heart failure (HF) ineligible for transplantation treated long-term with the Heartmate Vented Electric device had $48 \%$ reduction in mortality compared to medical management. For this pulsatile device, only aspirin was required for antithrombotic therapy. Bleeding and thrombotic complications were common, including 0.56 non-neurologic bleeding events per patient year (EPPY), 0.14 EPPY for peripheral embolism, 0.46 EPPY for perioperative bleeding, 0.06 EPPY LVAD thrombosis, and 0.75 EPPY for device malfunction (2).

The next major advance occurred with the advent of continuous flow (CF) devices. These devices required systemic anticoagulation. Compared to the Heartmate XVE, the Heartmate II had higher survival free from disabling stroke or need for device replacement. Bleeding, overall stroke, and pump thrombosis rates were not significantly different (3). The current generation Heartmate 3 has shown higher survival free of disabling stroke compared to Heartmate II (4).

\section{The scope of the problem}

Despite the survival advantage of LVAD over medical, the frequency and severity of adverse events (AE) represent a limitation of this therapy (2-9) (Table 1). The freedom to first occurrence of major $\mathrm{AE}$ (including infection, device malfunction, stroke, bleeding or death) at 6 months postimplantation is approximately $40 \%$ (10). The most frequent AEs are bleeding and thromboembolism episodes (11). AEs in LVAD patients lead to recurrent hospitalizations with an estimated 218 hospital admissions per 100 patients at 1 year post-implant (12). The balance between bleeding and thrombosis is vital in the management of patients supported by LVAD and represent a challenge to advanced HF cardiologists. Patient do not typically fit a "bleeder" or "clotter" profile, but they rather move along the bleeding/ thrombotic spectrum. The interplay between bleeding and thrombotic event has been clearly demonstrated, with

Table 1 Bleeding and thromboembolic complications from clinical trials of LVADs

\begin{tabular}{|c|c|c|c|}
\hline Clinical trial & Characteristics & \multicolumn{2}{|c|}{ Adverse events related to coagulation } \\
\hline \multirow{3}{*}{$\begin{array}{l}\text { REMATCH Trial (2) } \\
\text { (2001), PF }\end{array}$} & Mean age 68 y/o & Non-neurologic: 0.56 & Neurologic dysfunction: 0.39 \\
\hline & 68 patients received PF LVAD & Peri-operative: 0.46 & Peripheral embolism: 0.14 \\
\hline & 1-year survival $52 \%$ & & Pump thrombosis: 0.06 \\
\hline \multirow{4}{*}{$\begin{array}{l}\text { HM-2 BTT (5) (2007), } \\
\text { CF-Axial }\end{array}$} & Mean age $50 \mathrm{y} / \mathrm{o}$ & Bleeding requiring surgery: 0.78 & Embolic stroke: 0.13 \\
\hline & 133 patients received CF HM-2 & Bleeding requiring 2pRBC: 2.09 & TIA: 0.1 \\
\hline & Survival at 1 year $68 \%$ & Hemorrhagic stroke: 0.05 & Peripheral embolic: 0.15 \\
\hline & & & Pump thrombosis: 0.03 \\
\hline $\begin{array}{l}\text { HM-2 DT (3) (2009), CF- } \\
\text { Axial }\end{array}$ & Survival at 2-year $58 \%$ & Hemorrhagic stroke: 0.07 & Pump thrombosis: 0.02 \\
\hline \multirow{5}{*}{$\begin{array}{l}\text { HM-2 Post approval (6) } \\
\text { (2011), CF-Axial }\end{array}$} & 131 patients received $\mathrm{HM}-2$ & Bleeding: 1.44 & Embolic stroke: 0.06 \\
\hline & Survival at 1 year $85 \%$ & Hemorrhagic stroke: 0.01 & Total stroke: 0.08 \\
\hline & & & Peripheral embolism: 0.01 \\
\hline & & & Venous thromboembolic: 0.09 \\
\hline & & & Hemolysis: 0.04 \\
\hline
\end{tabular}

Table 1 (continued) 
Table 1 (continued)

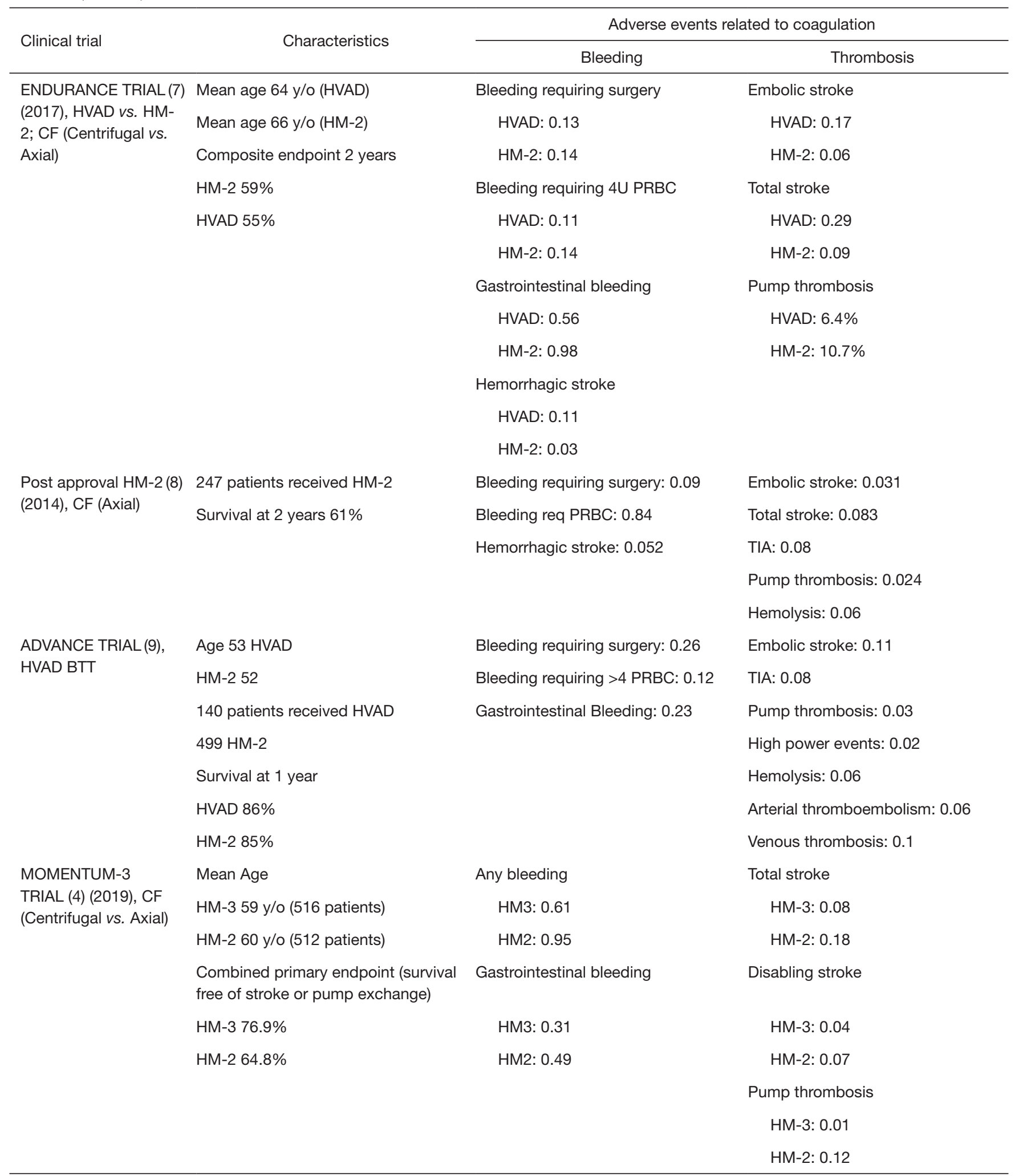

CF, continuous flow; PF, pulsatile flow; HM-2, Heartmate II; HM-3, Heartmate 3; HVAD, Heartware HVAD; BTT, bridge to transplant; PRBC, packed red blood cells; TIA, transient ischemic attack. 
Page 4 of 17

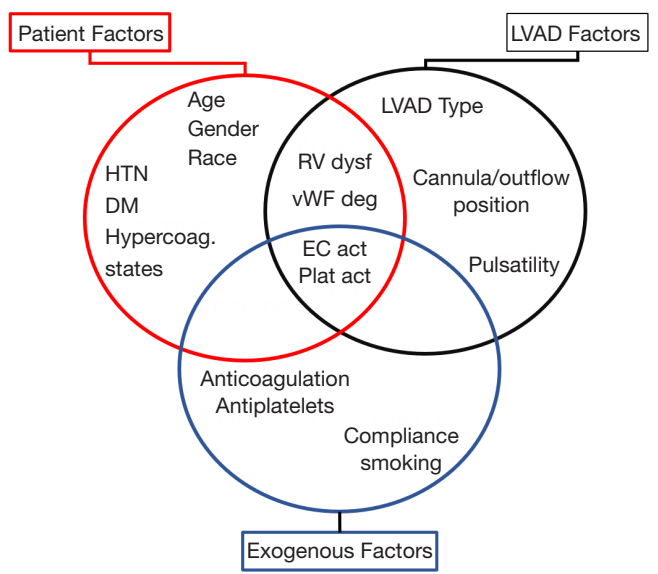

Figure 1 Interrelations between patient, LVAD and exogenous factors that lead to specific predisposition to thrombotic or bleeding events. DM, diabetes mellitus; HTN, hypertension; RV, right ventricle; vWF, von Wilebrand Factor; deg : degradation; EC act, endothelial cell activation; Plat act, platelet activation; LVAD, left ventricular assist device.

an increased risk of thromboembolic event following an episode of bleeding $(13,14)$ or an increased risk in bleeding episode as a result of a prior thrombotic event (15-17). In addition, infections $(18,19)$ and right ventricular failure $(20,21)$ have also been associated with increased risk for bleeding or thromboembolic events.

\section{Pathophysiology of bleeding and thromboembolic complications}

Factors predisposing to bleeding or thrombotic events can be related to the patient, the LVAD or external factors (Figure 1). The interplay between these factors determines whether a patient experiences a bleeding or thrombotic episode.

\section{LVAD-related factors}

Device type is directly related to the frequency of bleeding/ thrombotic events. Pulsatile LVADs had high rates of stroke, thromboembolic events, and device malfunction but no significant gastrointestinal bleeding (GIB) (2). The development of axial CF LVADs represented a significant improvement in technology, and frequency of device malfunction and thromboembolic events decreased significantly (5). However, with the loss of pulsatility the development of arteriovenous malformations (AVM) and recurrent GIB became an important problem (22). The
Loyaga-Rendon et al. Anticoagulation and antiplatelets in LVADs

introduction of the smaller centrifugal CF-LVAD (Heartware HVAD) broadened the utilization of LVADs, but with some concerns about increased frequency of strokes (7). The newest device, the HM3 has advantages over previous axial $2^{\text {nd }}$ generation devices with a very low frequency of pump thrombosis and a decreased frequency of disabling stroke with no changes in the frequency of GIB (4). Given the lower thromboembolic events, the HM3 has shifted the pendulum, and clinicians are now focusing on lower anticoagulation and antiplatelet protocols in an effort to decrease the frequency of GIB $(23,24)$. The variations in hemorrhagic or thrombotic events seen with different LVADs depends on multiple factors including LVAD hemocompatibility, which refers to the thrombotic response induced by the device on contact with blood. Multiple factors affect the hemocompatibility of the LVAD, including platelet activation due to shear stress (25), endothelial cell activation (26), degradation of von Willenbrand factor (27) and oxidative stress (28). LVADs differ in their ability to affect each of these parameters (29-31). In addition to LVAD itself, other parameters such as pulsatility (32) play an important role in the development of bleeding/thrombotic episodes.

\section{Patient-dependent factors}

Patient-related factors are also important in the development of hemorrhagic or thromboembolic events. Nonmodifiable factors include age, gender, and genetic polymorphisms. Advanced age is associated with increased frequency of both hemorrhagic and thrombotic events $(33,34)$. Female gender is associated with an increased risk of stroke (35). Hypercoagulable states are associated with increased in thromboembolic neurological events and mortality (36,37). Modifiable risk factors are also important. Hypertension is associated with hemorrhagic and ischemic strokes $(19,38,39)$. Some reports have suggested that diabetes mellitus (40) and atrial fibrillation (41) may also be associated with thromboembolic events. As mentioned earlier, infections $(18,19)$ and right ventricular dysfunction $(20,21)$ with increased systemic venous pressures are associated with cerebrovascular events and GIB respectively.

\section{Exogenous factors}

Other factors influencing the development of bleeding or thrombotic events relate to the intensity and strategy of anticoagulation and antiplatelet therapy. Compliance with medications, interactions with other medications or drugs 
as well as the use of tobacco (19) could affect the frequency of thrombotic/bleeding effects.

The interaction of pump, patient and external factors will create a unique combination in an specific individual, which requires individualized approaches prevent bleeding/ thrombotic events. For example, genetic variations are associated with differential responses to warfarin, aspirin, and clopidogrel, and identification of these patients early on could be an strategy to prevent bleeding/thromboembolic events (42).

\section{Platelet activation, clotting cascade and antiplatelet and antithromobotic agents}

Patients supported by LVADs require a combination of antiplatelet and antithrombotic agents. Physiologically the hemostatic system has a close interaction between platelets and clotting factors. Exposure of platelets to any foreign material will initiate their activation which is characterized by structural and functional changes that result in adhesion, degranulation and aggregation leading to the formation of a platelet rich plug (43). Simultaneously, the intrinsic and extrinsic pathways will be activated converging on the activation of Factor $\mathrm{X}$ which catalyze the formation of thrombin from prothrombin. Thrombin will promote the conversion of fibrin from fibrinogen. Thrombin can also potently activate platelets. Fibrin will stabilize the platelet plug and lead to clot formation. Shear stress is increased in LVAD supported patients which predisposed to platelet activation (25) and to Von Wilebrand factor degradation (27), leading to an increased risk for both clotting and bleeding. Figure 2 summarizes this physiology and pharmacological targets.

\section{Pre-implant antiplatelet and anticoagulation management}

Many patients with HF require anticoagulants/antiplatelet drugs for coronary artery disease, stents, atrial fibrillation, left ventricular thrombus, or deep venous thrombus. Only a few studies inform anticoagulation or antiplatelet management prior to LVAD implantation. The 2019 EACTS consensus statement on long-term MCS suggests withdrawal of dual antiplatelet therapy and/or vitamin $\mathrm{K}$ antagonists and use use of short-acting intravenous anticoagulation for bridging prior to LVAD (44).

Typical antiplatelet management would be to continue aspirin until the day of surgery and discontinue ticagrelor, clopidogrel, or prasugrel 3, 5 or 7 days before surgery respectively (45-47). There is higher risk of tamponade or chest reexploration for bleeding when surgery is performed within 24 hours after clopidogrel discontinuation. After 1-4 days of discontinuation, this risk continuously diminishes, although the risk of transfusion remains high. Ticagrelor's bleeding profile is similar to clopidgrel. Prasugrel, however, carries substantial higher risk of bleeding post cardiac surgery, and should be avoided in patients who are heart transplant or LVAD candidates. In the case of recent percutaneous coronary intervention (PCI), bridging with GPIIb/IIIa inhibitors may be considered, but there could be residual risk for stent thrombosis (48-51). Eptifibatide and Tirofiban should be discontinued at least 4 hours prior surgery, longer if significant renal dysfunction is present. Cangrelor, an intravenous antiplatelet drug with half life under 5 minutes and elimination independent of renal or liver function, may also be used to bridge patients to LVAD (52).

Outpatients taking a novel oral anticoagulant (e.g., dabigatran, apixaban, rivaroxaban) should be transitioned to coumadin or bridged with heparin/enoxaparin. If the patient is on coumadin and undergoing elective LVAD, bridging with unfractionated heparin (UFH) is recommended (53). Low molecular weight heparin (LMWH) should be discontinued 12 hours prior to surgery, and fondaparinux 24 hours prior to surgery. A longer interval may be necessary for patients with impaired renal function.

For urgent/emergent cases on patients receiving warfarin, prothrombin complex concentrates (PCC) may be considered to reverse Vitamin K antagonist effect $(54,55)$. A Cochrane systematic review on PCCs in non-LVAD cardiac operations demonstrated that PCC use does not reduce mortality or PRBC transfusion requirements but reverses vitamin K-induced coagulopathy without the need for transfusion of fresh frozen plasma (55).

\section{LVAD implantation: intraoperative anticoagulation management}

The standard approach to LVAD implantation is utilizing cardiopulmonary bypass (CPB), and UFH remains the most commonly used anticoagulant during CBP due to its short half life and existence of a reversal agent, protamine. Bolus administration of UFH based on weight is monitored by activated clotting time (ACT) target range from 400 to 500 seconds, "maximally activated level". Despite this widely accepted level of anticoagulation, there is no clear consensus on the accurate calculation of this initial dose of UFH. Options for calculating the initial heparin bolus 
A
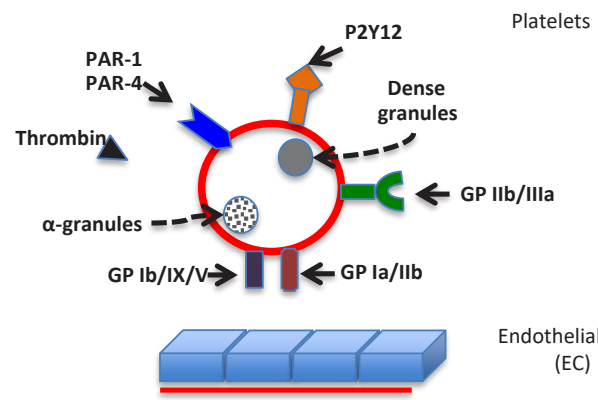

Endothelial Cells (EC)

Dense granules (ADP, ATP, Serotonine, Histamine, $\mathrm{Ca++}$ )

$\alpha$-granules (vWF, fibrinogen, TSP, PF4)

\section{C}

Platelet activation

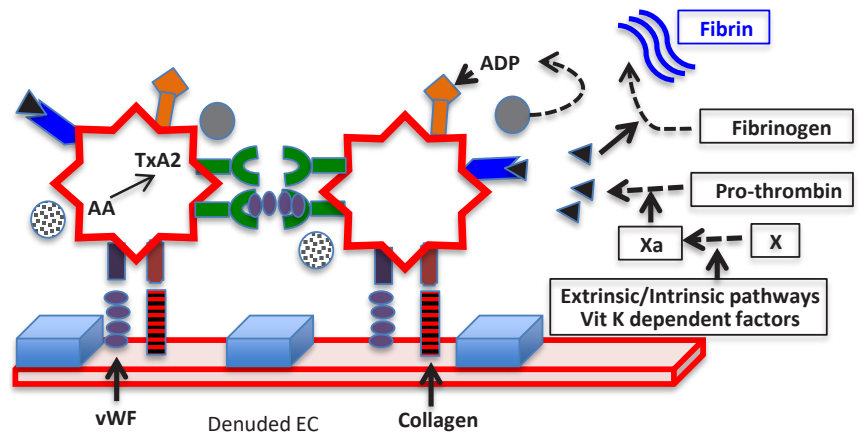

B

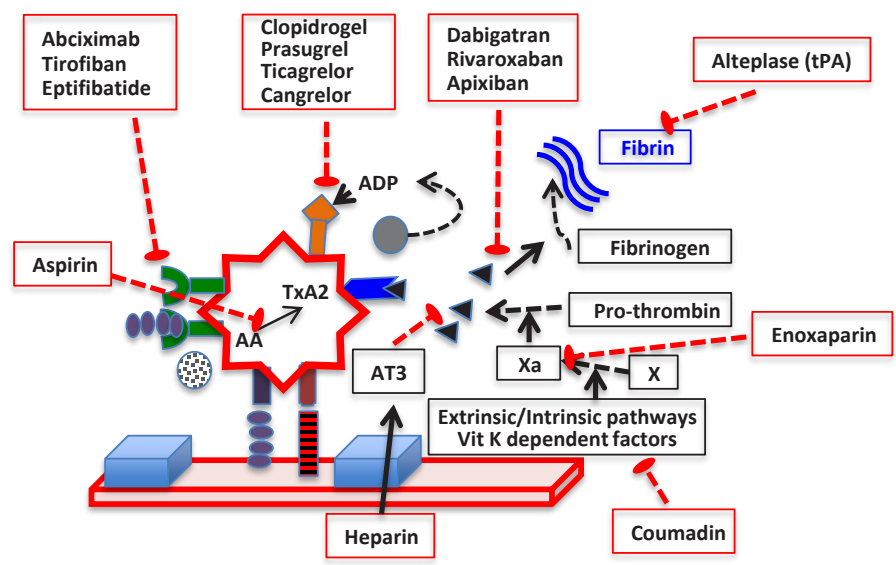

D

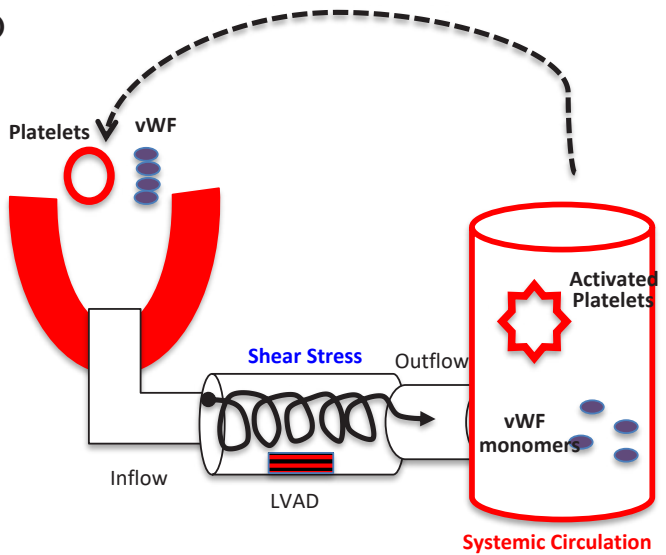

Figure 2 Platelet and Clotting cascade in LVAD patients. (A) Inactive platelets and its receptors and granules. (B) Hemostatic response to denuded endothelium. Panel depicts platelet activation (adhesion, aggregation, degranulation) and their interaction with the clotting cascade. (C) Depicts the multiple pharmacological targets to interfere with platelet function and clotting cascade. (D) Depicts the LVAD as a source of shear stress and foreign material that leads to platelet activation, $\mathrm{vWF}$ degradation. LVAD, left ventricular assist device; AA, arachidonic acid; ADP, adenosine diphosphate; AT3, antithrombin 3; GP, glycoprotein; LVAD, left ventricular assist device; vWF, von Willebrand factor.

include a fixed, weight-based dose, (e.g., $300 \mathrm{IU} / \mathrm{kg}$ ), or use of point-of-care tests that measure the whole blood sensitivity to heparin using an associated dose response. ACT should be monitored at regular intervals during CPB. The Society of Thoracic Surgeons (STS) guideline recommends ACT above 480 seconds during CPB (56). At the end of surgery, heparin is reversed with the calculated protamine reversal dose based on a titration to existing heparin in the blood. Level of anticoagulation is measured by ACT, point-of-care testing using protamine titration of heparinized blood samples, and thromboelastography with or without heparinase. Comparisons of these three methods suggest that ACT-based measurement of residual heparin effect is the least accurate $(57,58)$. A meta-analysis of standard weight-based versus titrated protamine dosing favors titrated dose protamine for heparin reversal because of less postoperative blood loss and decreased packed red blood cell transfusion (59). It is reasonable to limit the ratio of protamine/heparin to less than $2.6 \mathrm{mg}$ protamine per 100 units heparin because total doses above this ratio inhibit platelet function, prolong ACT, and increase the risk of bleeding (60).

\section{Management of heparin induced thrombocytopenia (HIT)}

Insufficient data exists regarding the management of acute/subacute HIT prior to MCS. CPB requires full anticoagulation, and the use of heparin in the setting of 
acute HIT (thrombocytopenia and positive heparin/platelet factor 4 antibody by enzyme-linked immunosorbent assay) is concerning because of the risk of thrombosis.

The 2012 College of Chest Physicians (ACCP) HIT guidelines recommend use of bivalirudin over non-heparin anticoagulants or heparin plus antiplatelet agents in patients with acute HIT (thrombocytopenic, HIT antibody positive) or subacute HIT (HIT antibody positive, normal platelets) who require urgent cardiac surgery. For patients requiring nonurgent surgery, it is recommended to wait until thrombocytopenia has resolved and HIT antibodies are negative. In patients with history of HIT but undetectable antibodies requiring cardiac surgery, brief intraoperativeonly heparin challenge is recommended. In patients with history of HIT in whom antibodies are still present, nonheparin anticoagulation is recommended (61).

However, in practice, the choice of anticoagulant during CPB in patients with HIT is not well defined, with several potential strategies: delaying surgery until HIT antibodies are negative (typically $\sim 100$ days after heparin cessation), intraoperative anticoagulation with direct thrombin inhibitor (DTI) such as argatroban or bivalirudin, use of heparin and intravenous antiplatelet agents(shortacting antiplatelet therapy potentially attenuates HIT antibody-induced platelet activation), and plasmapharesis. Irreversibility of intravenous DTIs makes these agents less appealing (62-66).

A few studies have reported on plasmapharesis prior to cardiac surgery. In one single-center study of 11 patients, plasma exchange was performed with fresh-frozen plasma replacement using a 1.3 plasma volume exchange. Plasmapharesis was performed before heparinization if patient was stable, but otherwise heparin was given, CBP initiated to stabilize patient, and plasmapheresis performed during CPB. Heparin is removed during plasmapheresis so additional heparin infusion was required. After a single plasmapheresis treatment, titers were reduced by $50-85 \%$. Six of 9 patients had negative titers after treatment, and the other three who had particularly high titers at baseline had reduced titers without clinical HIT (67)

Ramu et al. described a case-series of 4 patients requiring $\mathrm{CPB}$ with acute HIT, 2 of whom underwent heart transplantation (68). The strategy in this study involved pre-operative therapeutic plasma exchange until HIT ELISA turned negative, followed by intra-operative heparin. Post-operatively, patients were treated with nonheparin anticoagulants (bivalirudin or argatroban) bridged with warfarin. This approach successfully avoided non- heparin anticoagulants intra-operatively while preventing complications such as thrombosis and bleeding.

More evidence is required in this area to recommend one strategy over another, and HIT remains a significant perioperative management challenge.

\section{Perioperative antiplatelet and anticoagulation management}

Manufacturer guidelines exist regarding perioperative antiplatelet and anticoagulation management (Table 2) (69-71) but there are institutional variations.

Once UFH is started, the target anticoagulation range intially remains lower and is gradually increased during subsequent days [e.g., postoperative day 1-2 activated partial thromboplastin time (aPTT) goal of 40-60 seconds, and increase aPTT goal to 60-80 seconds on post-operative day 2-3] Anti-Xa monitoring is increasing in utility given discordance between aPTT and anti-Xa levels in LVAD patients with international normalized ratio (INR) above 1.8 (72).

Regarding antiplatelet therapy, recent clinical trials involving HVAD, HeartMate II and HeartMate 3 have recommended 81-325 $\mathrm{mg}$ daily aspirin (73). P2Y12 inhibitors can be considered in aspirin allergic patients. European centers that have treated patients with anticoagulation only (median INR 2.31) after HeartMate II implantation reported similar rates of bleeding and thrombotic complications compared to those treated with aspirin and anticoagulation at 2 years (74). In addition, a placebo-controlled trial of placebo or aspirin $81 \mathrm{mg}$ daily after HeartMate II $^{\mathrm{TM}}$ (PREVENT II) was performed in the US (36). At 6 months, the proportions of non-surgical bleeding, stroke, thromboembolic events, or ischemic or hemorrhagic strokes did not differ between placebo and ASA groups. At 12 months, more major bleeding events had occurred in the ASA compared to the placebo group but stroke remained comparable (75). The 2012 AHA Scientific Statement and 2013 ISHLT guidelines recommend both antiplatelet and anticoagulants in CF-LVADs $(73,76)$.

Whether UFH bridging should be used after LVAD implantation has been an area of debate. Consensus guidelines recommend beginning UFH once chest tube output has decreased and gradually increasing the target to the therapeutic range $(34,73)$. Although the field initially moved away from postoperative heparin because of reports of increased postoperative hemorrhage, the increased HeartMate II thrombosis rates led to a re-examination of 


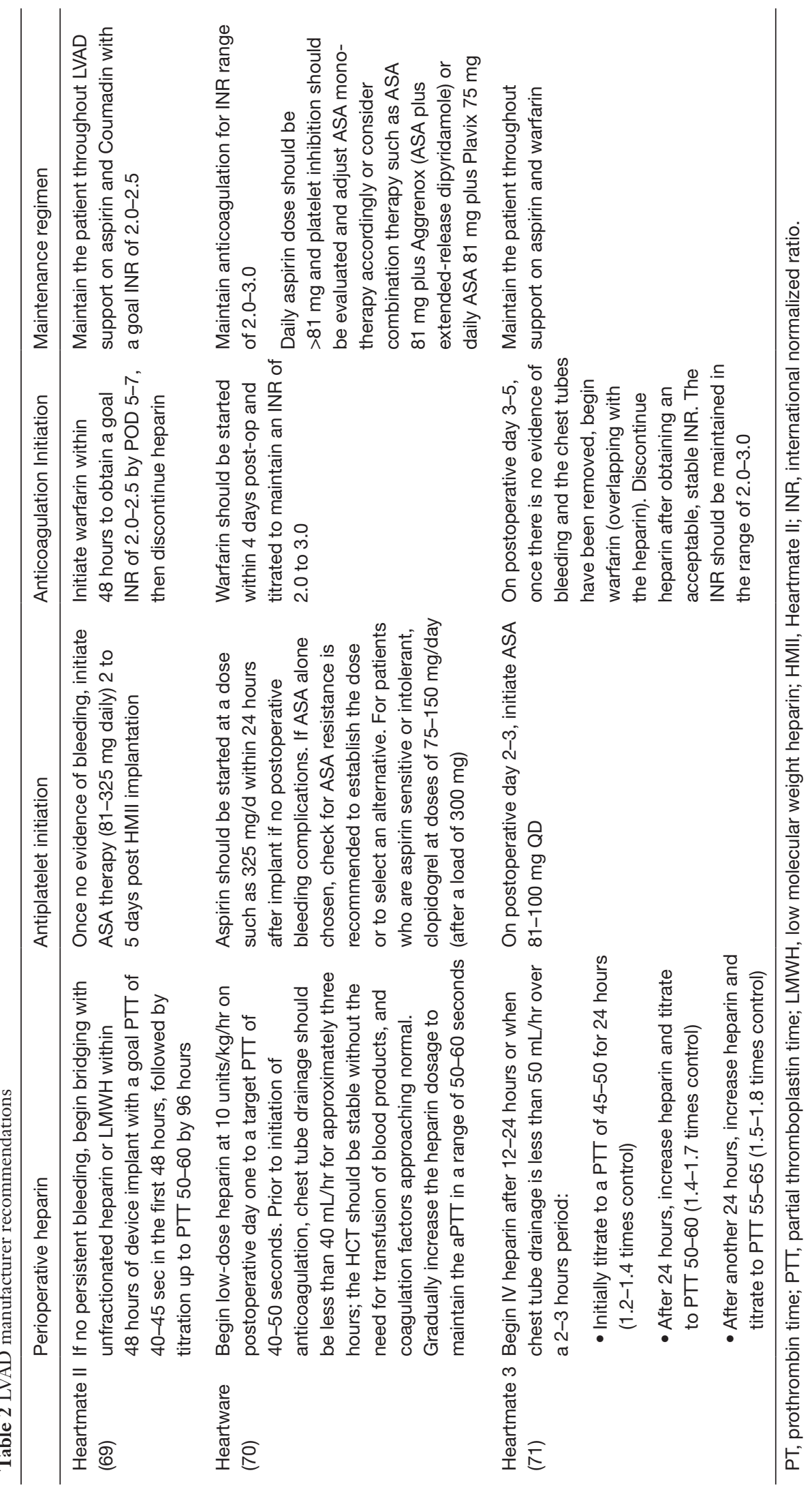


heparin bridging $(77,78)$. Ninety-five percent of patients received UFH in the PREVENTion of HeartMate II Pump Thrombosis trial. Pump thrombosis occurred in $1.9 \%$ of patients who received heparin bridging, maintained adequate pump speeds $(\geq 9,000$ revolutions per minute) and had all surgical recommendations followed, compared with $8.9 \%$ of other patients $(\mathrm{P}<0.01)(79)$. Thus, heparin bridging is recommended after LVAD implantation to bridge to therapeutic vitamin $\mathrm{K}$ antagonist (VKA) anticoagulation.

\section{Anticoagulation management of patient with LVAD at the time of transplant}

LVAD patients undergoing transplantation require full anticoagulation reversal before transplant. Vitamin $\mathrm{K}$ alone is not sufficient (80). Historically, fresh-frozen plasma (FFP) and low-dose 3 factor prothrombin complex concentrates (3F-PCCs) have most commonly been used for warfarin reversal before heart transplantation. After the introduction of 4F-PCC, this agent has gained significant popularity in perioperative anticoagulant reversal. $4 \mathrm{~F}-\mathrm{PC}$ is derived from human plasma and contains factors II, VII, IX, X, protein C, protein S, antithrombin III, and heparin (therefore 4F-PCC contraindicated in HIT) (81). 4F-reverses anticoagulation effects of VKA faster and with smaller volumes than FFP $(82,83)$. In a randomized study of anticoagulated patients needing urgent procedures, Goldstein et al. reported effective haemostasis in $78(90 \%)$ patients in the 4F-PCC group vs. $61(75 \%)$ patients in the FFP group. Rapid INR reduction ( $\leq 1.3$ at $0.5 \mathrm{~h}$ after infusion end) occurred in $48(55 \%)$ patients in the $4 \mathrm{~F}-\mathrm{PCC}$ group $v$ s. eight (10\%) patients in the FFP group (83). However, a 2019 retrospective study showed significantly higher risk of thromboembolic events in patients receiving 4F-PCC compared to $\mathrm{FFP}(17.7 \%$ vs. $2.7 \%, \mathrm{P}<0.001)$ for urgent warfarin reversal, raising concern for use of such products in the perioperative period (84).

Consensus guidelines from the American College of Cardiology recommend the use of FFP for the immediate reversal of anticoagulation in the setting of major bleed only when 4-factor PCC is not available (80). The dose of 4F-PCC depends on the INR at the time of administration and the patient's body weight (if INR 2 to $4: 25 \mathrm{U} / \mathrm{kg}$, INR 4 to 6: $35 \mathrm{U} / \mathrm{kg}$, INR >6: $50 \mathrm{U} / \mathrm{kg}$; max dose 5,000 U in patients over $100 \mathrm{~kg}$ ), and $4 \mathrm{~F}-\mathrm{PCC}$ should be coadministered with vitamin $\mathrm{K}$.

A recent single-center, retrospective study of 106 patients undergoing heart transplantation before and after implementation of a PCC-based preoperative warfarin reversal protocol revealed that the use of PCC decreases the need for FFP compared with the traditional approach of vitamin $\mathrm{K}$ and FFP (6 versus 8 units, $\mathrm{P}=0.002$ ) (85). Of the PCC cohort, 47 received 3 F-PCC and 10 received $4 F-P C C$. All patients receiving $4 \mathrm{~F}-\mathrm{PCC}$ achieved an INR $<1.5$ at the time of surgery, whereas 35 of $47(74.5 \%)$ patients receiving 3F-PCC achieved this INR goal. Additionally, the study reported a significant reduction in reversal time in the 4F-PCC group compared to the $3 \mathrm{~F}-\mathrm{PCC}$ group $(1.1 \pm 1.0$ vs. $3.4 \pm 3.3 \mathrm{~h}, \mathrm{P}<0.001)$. $4 \mathrm{~F}-\mathrm{PCC}$ dosing was adjusted based on initial INR and repeat INR at 15 minutes after infusion. This step-wise approach allowed use of lower doses of 4F-PCC than other studies and the FDAlabeled dose, which may be important in avoiding venous thromboembolism events.

\section{Warfarin considerations}

Maintenance of INR within therapeutic range is recommended for patients on warfarin and CF-LVADs, and time in therapeutic range (TTR) correlates with clinical outcomes (86). However, high TTR is difficult to achieve despite intense monitoring by LVAD teams, and a metaanalysis of 5 studies showed TTR of only $46.6 \%$ in CFLVADs (87). Low TTR may contribute to bleeding and thromboembolic complications.

There are substantial institutional variations in who manages a LVAD patient's warfarin: implanting center VAD coordinator/physician, implanting center anticoagulation clinic, outside anticoagulation clinic, non-LVAD clinician. A single-center study of 55 patients reported that anticoagulation managed by clinical pharmacists using patient self-tested (PST) point-of-care (POC) INR was associated with higher TTR (44.4\%vs. $30.6 \%, \mathrm{P}=0.026)$ compared to usual care with no difference in bleeding or thrombotic outcomes (88). In another single-center study, 26 patients whose warfarin managed by pharmacists in the first 3 months after LVAD had significantly higher TTR than historical controls (89). Others however, have reported no difference in INRs and clinical outcomes irrespective of the type of provider managing the patient's INR (90). A centralized interdisciplinary anticoagulation management system that integrates inpatient and outpatient management and has standardized guidelines may also improve anticoagulation management (91).

The inconvenience and cost of frequent laboratory visits 
for INR checks has led to adoption in some centers of PST with home POC INR machines. While generally adequate, concerns about quality control, precision, and accuracy remain. In a single-center study of 50 LVAD patients who underwent simultaneous POC and core lab INR testing found a median INR difference of 0.39 between the methods, with the POC test consistently overestimated INR, leading to concerns about inadequate anticoagulation in those with low-normal readings on POC tests (92). Another multicenter study of paired (but not simultaneous) POC and lab INR tests showed no statistically significant differences between either method, particularly when measured within 4 hours of each other (93).

\section{Novel oral anticoagulants}

Given the aforementioned issues with warfarin, there has been interest in novel oral anticoagulants (NOACs) in LVAD patients. Pollari reported a patient with recurrent GI bleeds on warfarin who was switched to apixaban without any bleeding or thromboembolic complications in the ensuing year (94). Another patient with resistance to vitamin $\mathrm{K}$ antagonists was treated with dabigatran without bleeding or thromboembolic complications until explant for recovery (95). A single-center study of 7 patients showed no increase in thrombotic complications and lower incidence of major bleeding with dabigatran compared with acenocoumarol (96). In contrast, a randomized controlled trial of 30 Heartware patients randomized to dabigatran or phenprocoumon was terminated early because of excess thromboembolic events (50\%) in the dabigatran group (97). A single-center series of 7 patients who had "failed" warfarin therapy with TTR of $30 \%$ were switched to apixaban or rivaroxaban, with lower thromboembolic or bleeding complications on NOACs (98). Given safety concerns, NOACs are not currently recommended as primary anticoagulation in LVADs.

\section{Pump thrombosis (PT)}

LVAD PT is a major LVAD complication with substantial morbidity and is the most common reason for device replacement. The etiology is complex, with patient-related, device-related, and management-related factors (99). For the Heartmate II device, there was a substantial increase in PT during 2011-2013, which resulted in intense investigation as to the contributing factors and management strategies, with some reversal of PT rates by $2014(100,101)$. A large proportion of the published literature on PT management pertains to the Heartmate II device and may not necessarily be applicable to other devices. PT risk is device dependent, and Heartmate III has a significantly more favorable PT profile than Heartmate II (1.4\% vs. $13.9 \%$ at 2 years) (4).

Small case series have reported variable degrees of success in treating PT with augmented or alternate anticoagulation, antiplatelet therapies, and thrombolysis $(11,102)$. Larger and aggregate studies report approximately $50 \%$ success of medical therapy in resolving PT, with similar success rates in Heartmate II and HVAD. A pooled analysis showed significant major bleeding risk of $29 \%$ in those receiving thrombolytics and $12 \%$ in those receiving non-thrombolytics (102). In a combined analysis of data from three experienced centers, mortality at 6 months in those treated medically was $48 \%$ compared to under $20 \%$ in those treated with pump exchange or transplantation (103). Early surgical pump exchange, often performed via subcostal approach, is the definitive and gold standard therapy for PT in patients who are surgical candidates (12). For nonsurgical candidates, anticoagulant and antiplatelet therapy may be individualized, based on presenting symptoms, clinical stability, and laboratory parameters such as INR at the time of pump thrombosis.

Given the challenges of treating PT, prevention is paramount. In addition to non-modifiable patient-related factors, management-related factors, such as mean arterial pressure $>90 \mathrm{mmHg}$, aspirin dose $\leq 81 \mathrm{mg}$ daily, and INR $\leq 2$ were risk factors for pump thrombosis in the Heartware ADVANCE study (104). In the Heartmate II PREVENT trial, adherence to recommended surgical techniques, heparin bridging after implantation, maintaining MAP $<90$ and INR 2-2.5, and running pump speed $>9,000$ was associated with a low rate of PT (79).

\section{Bleeding complications}

Among the more challenging situations in LVAD management include decisions on cessation and resumption of anticoagulation and antiplatelet therapies in patients who have had hemorrhagic complications. International guidelines provide only general recommendations (99).

\section{Intracranial hemorrhage}

Intracranial hemorrhage $(\mathrm{ICH})$ is a devastating complication with $50 \%$ early mortality and substantial disability in survivors. 
A few studies have examined in detail antithrombotic management strategies after ICH in LVAD patients. In a single center study of 36 patients who developed ICH while on pulsatile and CF LVADs, warfarin was withheld in $61 \%$ and aspirin was withheld in $47 \%$. Anticoagulation was reversed with $\mathrm{FFP}$ in $61 \%$ and platelets were administered in $39 \%$. No acute thromboembolic events were seen. Aspirin was resumed after a median of 6 days and warfarin resumed after a median of 10.5 days with no recurrent bleeds. Patients with subdural hemorrhage $(\mathrm{SDH})$ and subarachnoid hemorrhage (SAH) had better outcomes than those with intraparenchymal hemorrhage (IPH) (105). Another single center study of 27 LVAD patients with ICH, those with IPH had a higher rate of anticoagulant (90\%) and antiplatelet $(50 \%)$ reversal than those with SDH or $\mathrm{SAH}$. Antiplatelet resumption occurred at mean of 6 days and anticoagulation at a mean of 3.4 days in this group. No patients had LVAD thrombosis with anticoagulation reversal (106). Wong and colleagues evaluated 31 patients with ICH and demonstrated no thromboembolic events in those who received PCC. Also, patients with small bleeds (mean ICH volume $0.4 \mathrm{~cm}^{3}$ ) were managed conservatively without active reversal, with no increased hemorrhage (107). In another single center study of 405 LVAD patients, ICH occurred in 39 (10\%). Among these, 27 received antithrombotic reversal (PCC, Vitamin K, and/or FFP). Eight of the 27 had inadequate coagulopathy reversal (INR GE 1.4). ICH expansion or death before repeat imaging occurred in $38 \%$ of patients with inadequate coagulopathy reversal vs. $30 \%$ of patients with adequate coagulopathy reversal. One thrombotic event (deep venous thrombosis) occurred with reversal. Antithrombotics were resumed in all 17 survivors (12 resumed warfarin + antiplatelet, 4 resumed antiplatelet, of whom 1 crossed to the warfarin + antiplatelet group, and 2 resumed warfarin alone). The median time to resumption was 8 days for aspirin and 14 days for warfarin. There were 4 recurrent intracranial hemorrhages in the group (2 ICH (intracerebral hemorrhage), $1 \mathrm{SDH}$, $1 \mathrm{SAH})$, none of which were fatal. Three of the 4 recurrent $\mathrm{ICH}$ were in the aspirin + warfarin group, and two ICH occurred during heparin-warfarin bridge. There was a trend for more thrombotic events in the antiplatelet alone resumption group. The median time to ischemic stroke was 428 days after antithrombotic resumption and median time to recurrent hemorrhagic stroke was 7 days after antithrombotic resumption. The authors conclude in LVAD patients with $\mathrm{ICH}$, anticoagulation reversal, preferably with PCC appears to be safe, the timing of anticoagulation resumption may need to be extended to 30 days after index event given early risk of recurrent hemorrhage, and heparin bridge should be avoided (103).

\section{Gastrointestinal bleeding}

Gastrointestinal bleeding (GIB) occurs in $12-25 \%$ of patients in the first year after LVAD (12). Rates of GIB in LVAD patients are substantially higher than in other populations on antiplatelets or anticoagulants. The pathophysiology of GIB on LVAD is multifactorial and includes acquired Von Willebrand syndrome, angiodysplasias likely related to low pulsatility, altered nitric oxide metabolism, and right ventricular (RV) dysfunction $(21,108)$. In addition to adjustment of antiplatelet and anticoagulant agents, other management approaches with variable success include pump speed adjustment to induce pulsatility, volume, inotropes, and VAD management to treat RV dysfunction, octeotride, vWF concentrate, desmopressin, danazol, thalidomide, ACE inhibitors, and estrogen $(108,109)$. Finally, transplantation when available is a highly effective intervention for people with recurrent GIB (110).

The 2013 ISHLT MCS guidelines provided, in the absence of adequately powered studies, several consensus (level of evidence C) recommendations for management of GIB in LVAD patients. These included cessation of anticoagulant/antiplatelet drugs until bleeding resolves in the absence of pump dysfunction, reversal of anticoagulation in the setting of elevated INR and clinically significant GIB, and resumption of antiplatelet and anticoagulation therapy after resolution of a first episode of GIB. For recurrent GIB without a source or source not amenable to treatment, it was recommended that the dose, intensity, or even the use of antiplatelet drugs or warfarin should be re-evaluated (73). The 2020 guideline update notes that reducing speed to induce pulsatility may decrease GIB risk.

Decisions regarding antiplatelet and anticoagulation management are institution-specific and generally made on an individualized basis based on severity of bleeding, endoscopic findings and risk of recurrence, history of prior GIB, and risk or history other thrombotic complications. Recurrent GIB risk remains significant despite cessation of anticoagulation or antiplatelet agents. In an important analysis of 100 patients with HM II LVAD and prior bleeding complications, reduced antithrombotic therapy with warfarin only $(38 \%)$, aspirin only $(28 \%)$, or no antithrombotic agents (34\%) was still associated with 71 bleeding events within 1 year of reduced antithrombotic, 
and the most common event was GIB (22) with comparable rates across the three antithrombotic subgroups. Importantly stroke occurred in $6 \%$ and pump thrombosis in $7 \%$ in the year after initiation of reduced antithrombotics (14).

\section{LVAD and artificial valves}

Patients with aortic and mitral valve disease or prior valve replacements may develop advanced $\mathrm{HF}$ requiring LVAD therapy. Limited experience suggests that for pre-existing bioprosthetic or mechanical mitral valves, no surgical modification is required (111). Heparin should be started early, as soon as no significant postoperative bleeding is observed. Aspirin should INR target should be 2.5-3.5 for patients with mechanical mitral valve and current generation CF LVADs. Pre-existing mitral regurgitation usually requires no therapy and generally expected to improve after LVAD, although this is increasingly being recognized as a complicated matter, with intense ongoing investigation (112).

Aortic insufficiency impairs LVAD function. For preexisting aortic insufficiency, valve oversewing, leaflet repair, or bioprosthetic aortic valve replacement is recommended. Mechanical aortic valves risk valve and root thrombus and should not be implanted. Patients with pre-existing mechanical aortic valves may be treated with patch closure or replacement with a bioprosthetic aortic valve.

\section{LVAD and noncardiac surgery}

Patients on LVAD therapy may require non-cardiac surgery, which can usually be safely performed, but there are unique antiplatelet or anticoagulant considerations. The nature of surgical intervention being performed (e.g., neurosurgical $v s$. endoscopic or dermatologic) as well as patient's individual bleeding and thrombotic history influence the management strategy. For elective surgeries, active reversal (e.g., Vitamin K, PCC, FFP, platelet transfusions) is generally not performed, but passive reversal, often combined with a heparin or enoxaparin bridge is a common approach (113). For urgent or emergent procedures, the nature of the surgical problems, anticipated surgery, and pre-existing bleeding and thrombotic profile dictate the most appropriate approach and is best done collaboratively with the surgeon and the LVAD team.

\section{Conclusion}

Bleeding and thromboembolism are key complications of
LVADs. A thorough understanding of device, patient, and management, including anticoagulation and antiplatelet therapies are important in optimizing VAD outcomes.

\section{Acknowledgments}

Funding: None.

\section{Footnote}

Provenance and Peer Review: This article was commissioned by the Guest Editors (Dr. Debabrata Mukherjee and Dr. Jose B. Cruz Rodriguez) for the series "Heart Failure Update and Advances in 2021" published in Annals of Translational Medicine. The article was sent for external peer review organized by the Guest Editors and the editorial office.

Conflicts of Interest: All authors have completed the ICMJE uniform disclosure form (available at http://dx.doi. org/10.21037/atm-20-4849). The series "Heart Failure Update and Advances in 2021" was commissioned by the editorial office without any funding or sponsorship. The authors have no other conflicts of interest to declare.

Ethical Statement: The authors are accountable for all aspects of the work in ensuring that questions related to the accuracy or integrity of any part of the work are appropriately investigated and resolved.

Open Access Statement: This is an Open Access article distributed in accordance with the Creative Commons Attribution-NonCommercial-NoDerivs 4.0 International License (CC BY-NC-ND 4.0), which permits the noncommercial replication and distribution of the article with the strict proviso that no changes or edits are made and the original work is properly cited (including links to both the formal publication through the relevant DOI and the license). See: https://creativecommons.org/licenses/by-nc-nd/4.0/.

\section{References}

1. DeBakey ME. Left ventricular bypass pump for cardiac assistance. Clinical experience. Am J Cardiol 1971;27:3-11.

2. Rose EA, Gelijns AC, Moskowitz AJ, et al. Long-term use of a left ventricular assist device for end-stage heart failure. N Engl J Med 2001;345:1435-43.

3. Slaughter MS, Rogers JG, Milano CA, et al. Advanced 
heart failure treated with continuous-flow left ventricular assist device. N Engl J Med 2009;361:2241-51.

4. Mehra MR, Uriel N, Naka Y, et al. A Fully Magnetically Levitated Left Ventricular Assist Device - Final Report. N Engl J Med 2019;380:1618-27.

5. Miller LW, Pagani FD, Russell SD, et al. Use of a continuous-flow device in patients awaiting heart transplantation. N Engl J Med 2007;357:885-96.

6. Starling RC, Naka Y, Boyle AJ, et al. Results of the post-U.S. Food and Drug Administration-approval study with a continuous flow left ventricular assist device as a bridge to heart transplantation: a prospective study using the INTERMACS (Interagency Registry for Mechanically Assisted Circulatory Support). J Am Coll Cardiol 2011;57:1890-8.

7. Rogers JG, Pagani FD, Tatooles AJ, et al. Intrapericardial Left Ventricular Assist Device for Advanced Heart Failure. N Engl J Med 2017;376:451-60.

8. Jorde UP, Kushwaha SS, Tatooles AJ, et al. Results of the destination therapy post-food and drug administration approval study with a continuous flow left ventricular assist device: a prospective study using the INTERMACS registry (Interagency Registry for Mechanically Assisted Circulatory Support). J Am Coll Cardiol 2014;63:1751-7.

9. Aaronson KD, Slaughter MS, Miller LW, et al. Use of an intrapericardial, continuous-flow, centrifugal pump in patients awaiting heart transplantation. Circulation 2012;125:3191-200.

10. Kirklin JK, Pagani FD, Kormos RL, et al. Eighth annual INTERMACS report: Special focus on framing the impact of adverse events. J Heart Lung Transplant 2017;36:1080-6.

11. Loyaga-Rendon RY, Jani M, Fermin D, et al. Prevention and Treatment of Thrombotic and Hemorrhagic Complications in Patients Supported by ContinuousFlow Left Ventricular Assist Devices. Curr Heart Fail Rep 2017;14:465-77.

12. Teuteberg JJ, Cleveland JC, Jr., Cowger J, et al. The Society of Thoracic Surgeons Intermacs 2019 Annual Report: The Changing Landscape of Devices and Indications. Ann Thorac Surg 2020;109:649-60.

13. Stulak JM, Lee D, Haft JW, et al. Gastrointestinal bleeding and subsequent risk of thromboembolic events during support with a left ventricular assist device. J Heart Lung Transplant 2014;33:60-4.

14. Katz JN, Adamson RM, John R, et al. Safety of reduced anti-thrombotic strategies in HeartMate II patients: A one-year analysis of the US-TRACE Study. J Heart Lung
Transplant 2015;34:1542-8.

15. Schlendorf K, Patel CB, Gehrig T, et al. Thrombolytic therapy for thrombosis of continuous flow ventricular assist devices. J Card Fail 2014;20:91-7.

16. Tellor BR, Smith JR, Prasad SM, et al. The use of eptifibatide for suspected pump thrombus or thrombosis in patients with left ventricular assist devices. J Heart Lung Transplant 2014;33:94-101.

17. Stulak JM, Dunlay SM, Sharma S, et al. Treatment of device thrombus in the HeartWare HVAD: Success and outcomes depend significantly on the initial treatment strategy. J Heart Lung Transplant 2015;34:1535-41.

18. Trachtenberg BH, Cordero-Reyes AM, Aldeiri M, et al. Persistent blood stream infection in patients supported with a continuous-flow left ventricular assist device is associated with an increased risk of cerebrovascular accidents. J Card Fail 2015;21:119-25.

19. Frontera JA, Starling R, Cho SM, et al. Risk factors, mortality, and timing of ischemic and hemorrhagic stroke with left ventricular assist devices. J Heart Lung Transplant 2017;36:673-83.

20. Sparrow CT, Nassif ME, Raymer DS, et al. Pre-Operative Right Ventricular Dysfunction Is Associated With Gastrointestinal Bleeding in Patients Supported With Continuous-Flow Left Ventricular Assist Devices. JACC Heart Fail 2015;3:956-64.

21. Joly JM, El-Dabh A, Kirklin JK, et al. High Right Atrial Pressure and Low Pulse Pressure Predict Gastrointestinal Bleeding in Patients With Left Ventricular Assist Device. J Card Fail 2018;24:487-93.

22. Birks EJ. Stopping LVAD Bleeding: A Piece of the Puzzle. Circ Res 2017;121:902-4.

23. Netuka I, Ivák P, Tučanová Z, et al. Evaluation of lowintensity anti-coagulation with a fully magnetically levitated centrifugal-flow circulatory pump-the MAGENTUM 1 study. J Heart Lung Transplant 2018;37:579-86.

24. Saeed O, Colombo PC, Mehra MR, et al. Effect of aspirin dose on hemocompatibility-related outcomes with a magnetically levitated left ventricular assist device: An analysis from the MOMENTUM 3 study. J Heart Lung Transplant 2020;39:518-25.

25. Consolo F, Sferrazza G, Motolone G, et al. Platelet activation is a preoperative risk factor for the development of thromboembolic complications in patients with continuous-flow left ventricular assist device. Eur J Heart Fail 2018;20:792-800.

26. Apostoli A, Bianchi V, Bono N, et al. Prothrombotic activity of cytokine-activated endothelial cells and shear- 
activated platelets in the setting of ventricular assist device support. J Heart Lung Transplant 2019;38:658-67.

27. Jhun CS, Siedlecki C, Xu L, et al. Stress and Exposure Time on von Willebrand Factor Degradation. Artif Organs 2019;43:199-206.

28. Mondal NK, Chen Z, Trivedi JR, et al. Oxidative stress induced modulation of platelet integrin $\alpha 2 \mathrm{~b} \beta 3$ expression and shedding may predict the risk of major bleeding in heart failure patients supported by continuous flow left ventricular assist devices. Thromb Res 2017;158:140-8.

29. Zayat R, Moza A, Grottke O, et al. In vitro comparison of the hemocompatibility of two centrifugal left ventricular assist devices. J Thorac Cardiovasc Surg 2019;157:591-9.e4.

30. Netuka I, Kvasnička T, Kvasnička J, et al. Evaluation of von Willebrand factor with a fully magnetically levitated centrifugal continuous-flow left ventricular assist device in advanced heart failure. J Heart Lung Transplant 2016;35:860-7.

31. Berk ZBK, Zhang J, Chen Z, et al. Evaluation of in vitro hemolysis and platelet activation of a newly developed maglev LVAD and two clinically used LVADs with human blood. Artif Organs 2019;43:870-9.

32. Wever-Pinzon O, Selzman CH, Drakos SG, et al. Pulsatility and the risk of nonsurgical bleeding in patients supported with the continuous-flow left ventricular assist device HeartMate II. Circ Heart Fail 2013;6:517-26.

33. Taylor C, Bittner K, Bartell N, et al. Outcomes of gastrointestinal bleeding in patients with left ventricular assist devices: a tertiary care experience. Endosc Int Open 2020;8:E301-9.

34. Kirklin JK, Naftel DC, Myers SL, et al. Quantifying the impact from stroke during support with continuous flow ventricular assist devices: An STS INTERMACS analysis. J Heart Lung Transplant 2020;39:782-94.

35. Acharya D, Loyaga-Rendon R, Morgan CJ, et al. INTERMACS Analysis of Stroke During Support With Continuous-Flow Left Ventricular Assist Devices: Risk Factors and Outcomes. JACC Heart Fail 2017;5:703-11.

36. Fried J, Levin AP, Mody KM, et al. Prior hematologic conditions carry a high morbidity and mortality in patients supported with continuous-flow left ventricular assist devices. J Heart Lung Transplant 2014;33:1119-25.

37. Alvarez P, Cordero-Reyes AM, Uribe C, et al. Acquired and Hereditary Hypercoagulable States in Patients with Continuous Flow Left Ventricular Assist Devices: Prevalence and Thrombotic Complications. J Card Fail 2016;22:501-11.

38. Nassif ME, Tibrewala A, Raymer DS, et al. Systolic blood pressure on discharge after left ventricular assist device insertion is associated with subsequent stroke. J Heart Lung Transplant 2015;34:503-8.

39. Pinsino A, Castagna F, Zuver AM, et al. Prognostic implications of serial outpatient blood pressure measurements in patients with an axial continuous-flow left ventricular assist device. J Heart Lung Transplant 2019;38:396-405.

40. Willey JZ, Gavalas MV, Trinh PN, et al. Outcomes after stroke complicating left ventricular assist device. J Heart Lung Transplant 2016;35:1003-9.

41. Stulak JM, Deo S, Schirger J, et al. Preoperative atrial fibrillation increases risk of thromboembolic events after left ventricular assist device implantation. Ann Thorac Surg 2013;96:2161-7.

42. Montalto A, Comisso M, Cammardella A, et al. Early Aspirin Nonresponders Identification by Routine Use of Aggregometry Test in Patients With Left Ventricle Assist Devices Reduces the Risk of Pump Thrombosis. Transplant Proc 2019;51:2986-90.

43. Saad J, Asuka E, Schoenberger L. Physiology, Platelet Activation. StatPearls. Treasure Island (FL): StatPearls Publishing Copyright (C) 2020, StatPearls Publishing LLC.; 2020.

44. Potapov EV, Antonides C, Crespo-Leiro MG, et al. 2019 EACTS Expert Consensus on long-term mechanical circulatory support. Eur J Cardiothorac Surg 2019;56:230-70.

45. Smith PK, Goodnough LT, Levy JH, et al. Mortality benefit with prasugrel in the TRITON-TIMI 38 coronary artery bypass grafting cohort: risk-adjusted retrospective data analysis. J Am Coll Cardiol 2012;60:388-96.

46. Hansson EC, Jideus L, Aberg B, et al. Coronary artery bypass grafting-related bleeding complications in patients treated with ticagrelor or clopidogrel: a nationwide study. Eur Heart J 2016;37:189-97.

47. Gherli R, Mariscalco G, Dalen M, et al. Safety of Preoperative Use of Ticagrelor With or Without Aspirin Compared With Aspirin Alone in Patients With Acute Coronary Syndromes Undergoing Coronary Artery Bypass Grafting. JAMA Cardiol 2016;1:921-8.

48. Windecker S, Kolh P, Alfonso F, et al. 2014 ESC/EACTS Guidelines on myocardial revascularization. Kardiol Pol 2014;72:1253-379.

49. Ferraris VA, Saha SP, Oestreich JH, et al. 2012 update to the Society of Thoracic Surgeons guideline on use of antiplatelet drugs in patients having cardiac and noncardiac operations. Ann Thorac Surg 2012;94:1761-81. 
50. Storey RF, Bliden KP, Ecob R, et al. Earlier recovery of platelet function after discontinuation of treatment with ticagrelor compared with clopidogrel in patients with high antiplatelet responses. J Thromb Haemost 2011;9:1730-7.

51. Alshawabkeh LI, Prasad A, Lenkovsky F, et al. Outcomes of a preoperative "bridging" strategy with glycoprotein IIb/ IIIa inhibitors to prevent perioperative stent thrombosis in patients with drug-eluting stents who undergo surgery necessitating interruption of thienopyridine administration. EuroIntervention 2013;9:204-11.

52. Washam JB, Yerokun B, Patel CB, et al. Cangrelor use prior to left ventricular assist device surgery: a case series. J Thromb Thrombolysis 2018;46:131-3.

53. Douketis JD, Spyropoulos AC, Kaatz S, et al. Perioperative Bridging Anticoagulation in Patients with Atrial Fibrillation. N Engl J Med 2015;373:823-33.

54. Demeyere R, Gillardin S, Arnout J, et al. Comparison of fresh frozen plasma and prothrombin complex concentrate for the reversal of oral anticoagulants in patients undergoing cardiopulmonary bypass surgery: a randomized study. Vox Sang 2010;99:251-60.

55. Johansen M, Wikkelso A, Lunde J, et al. Prothrombin complex concentrate for reversal of vitamin $\mathrm{K}$ antagonist treatment in bleeding and non-bleeding patients. Cochrane Database Syst Rev 2015;2015:CD010555.

56. Shore-Lesserson L, Baker RA, Ferraris VA, et al. The Society of Thoracic Surgeons, The Society of Cardiovascular Anesthesiologists, and The American Society of ExtraCorporeal Technology: Clinical Practice Guidelines-Anticoagulation During Cardiopulmonary Bypass. Ann Thorac Surg 2018;105:650-62.

57. Galeone A, Rotunno C, Guida P, et al. Monitoring incomplete heparin reversal and heparin rebound after cardiac surgery. J Cardiothorac Vasc Anesth 2013;27:853-8.

58. Murray DJ, Brosnahan WJ, Pennell B, et al. Heparin detection by the activated coagulation time: a comparison of the sensitivity of coagulation tests and heparin assays. J Cardiothorac Vasc Anesth 1997;11:24-8.

59. Wang J, Ma HP, Zheng H. Blood loss after cardiopulmonary bypass, standard vs titrated protamine: a meta-analysis. Neth J Med 2013;71:123-7.

60. Carr ME, Jr., Carr SL. At high heparin concentrations, protamine concentrations which reverse heparin anticoagulant effects are insufficient to reverse heparin anti-platelet effects. Thromb Res 1994;75:617-30.

61. Linkins LA, Dans AL, Moores LK, et al. Treatment and prevention of heparin-induced thrombocytopenia: Antithrombotic Therapy and Prevention of Thrombosis, 9th ed: American College of Chest Physicians Evidence-Based Clinical Practice Guidelines. Chest 2012;141:e495S-e530S.

62. Zucker MJ, Sabnani I, Baran DA, et al. Cardiac transplantation and/or mechanical circulatory support device placement using heparin anti-coagulation in the presence of acute heparin-induced thrombocytopenia. J Heart Lung Transplant 2010;29:53-60.

63. Potzsch B, Klovekorn WP, Madlener K. Use of heparin during cardiopulmonary bypass in patients with a history of heparin-induced thrombocytopenia. N Engl J Med 2000;343:515.

64. Koster A, Loebe M, Mertzlufft F, et al. Cardiopulmonary bypass in a patient with heparin-induced thrombocytopenia II and impaired renal function using heparin and the platelet GP IIb/IIIa inhibitor tirofiban as anticoagulant. Ann Thorac Surg 2000;70:2160-1.

65. Dyke CM, Smedira NG, Koster A, et al. A comparison of bivalirudin to heparin with protamine reversal in patients undergoing cardiac surgery with cardiopulmonary bypass: the EVOLUTION-ON study. J Thorac Cardiovasc Surg 2006;131:533-9.

66. Welsby IJ, Um J, Milano CA, et al. Plasmapheresis and heparin reexposure as a management strategy for cardiac surgical patients with heparin-induced thrombocytopenia. Anesth Analg 2010;110:30-5.

67. Brady J, Riccio JA, Yumen OH, et al. Plasmapheresis. A therapeutic option in the management of heparinassociated thrombocytopenia with thrombosis. Am J Clin Pathol 1991;96:394-7.

68. Ramu B, Cogswell RJ, Reding MT, et al. Plasma exchange to remove heparin-induced thrombocytopenia antibodies and the use of heparin during cardiopulmonary bypass in critically ill cardiac patients. J Heart Lung Transplant 2018;37:1038-40.

69. Corporation T. Heartmate II Instructions for Use. 2017. Available online: https://manuals.sjm.com/ Search-Form? re=North-America\&cc $=$ US \& $1 n=E N$ \&ct=professional $\&$ fam $=17 \mathrm{f} 61 \mathrm{ec} 6-2 \mathrm{a} 4 \mathrm{c}-4 \mathrm{~d} 8 \mathrm{~d}-\mathrm{a} 364-$ 881da438eb89\&cat=b18f3d02-acc5-41a5-be09934302b1b718\&seg=dae86226-3cf7-4b5f-8fb47947 b734ced6\&qry=heartmate $\% 20$ II\&ipp $=10$

70. Corportation H. Heartware HVAD IFU. Available online: https://www.accessdata.fda.gov/cdrh_docs/pdf10/ P100047S090D.pdf

71. Corporation A. Heartmate III Instructions for Use 2019. Available online: https://manuals.sjm.com/ Search-Form? re=North-America\&cc=US\&ln=EN 
\&ct=professional $\&$ fam $=17 \mathrm{f} 61 \mathrm{ec} 6-2 \mathrm{a} 4 \mathrm{c}-4 \mathrm{~d} 8 \mathrm{~d}-\mathrm{a} 364-$ 881da438eb89\&cat=b18f3d02-acc5-41a5-be09934302b1b718\&seg=dae86226-3cf7-4b5f-8fb4$7947 b 734$ ced6\&qry=heartmate $\% 203 \&$ ipp $=10$

72. Adatya S, Sunny R, Fitzpatrick MJ, et al. Coagulation factor abnormalities related to discordance between antifactor $\mathrm{Xa}$ and activated partial thromboplastin time in patients supported with continuous-flow left ventricular assist devices. J Heart Lung Transplant 2016;35:1311-20.

73. Feldman D, Pamboukian SV, Teuteberg JJ, et al. The 2013 International Society for Heart and Lung Transplantation Guidelines for mechanical circulatory support: executive summary. J Heart Lung Transplant 2013;32:157-87.

74. Netuka I, Litzler PY, Berchtold-Herz M, et al. Outcomes in HeartMate II Patients With No Antiplatelet Therapy: 2-Year Results From the European TRACE Study. Ann Thorac Surg 2017;103:1262-8.

75. Jorde UP, Katz JN, Colombo PC, et al. PREVENTion of non-surgical bleeding by management of HeartMate II patients without anti-platelet therapy (PREVENT II) trial. J Heart Lung Transplant 2020;39:838-40.

76. Peura JL, Colvin-Adams M, Francis GS, et al. Recommendations for the use of mechanical circulatory support: device strategies and patient selection: a scientific statement from the American Heart Association. Circulation 2012;126:2648-67.

77. Slaughter MS, Naka Y, John R, et al. Post-operative heparin may not be required for transitioning patients with a HeartMate II left ventricular assist system to long-term warfarin therapy. J Heart Lung Transplant 2010;29:616-24.

78. Starling RC, Moazami N, Silvestry SC, et al. Unexpected abrupt increase in left ventricular assist device thrombosis. N Engl J Med 2014;370:33-40.

79. Maltais S, Kilic A, Nathan S, et al. PREVENtion of HeartMate II Pump Thrombosis Through Clinical Management: The PREVENT multi-center study. J Heart Lung Transplant 2017;36:1-12.

80. Tomaselli GF, Mahaffey KW, Cuker A, et al. 2017 ACC Expert Consensus Decision Pathway on Management of Bleeding in Patients on Oral Anticoagulants: A Report of the American College of Cardiology Task Force on Expert Consensus Decision Pathways. J Am Coll Cardiol 2017;70:3042-67.

81. Kcentra Prescribing Information. Available online: https:// labeling.cslbehring.com/PI/US/Kcentra/EN/KcentraPrescribing-Information.pdf

82. Nuckles KB, Pratt JH, Cameron CM, et al. Case series of four-factor prothrombin complex concentrate for warfarin reversal before heart transplantation. Transplant Proc 2015;47:841-3.

83. Goldstein JN, Refaai MA, Milling TJ, Jr., et al. Fourfactor prothrombin complex concentrate versus plasma for rapid vitamin $\mathrm{K}$ antagonist reversal in patients needing urgent surgical or invasive interventions: a phase 3b, open-label, non-inferiority, randomised trial. Lancet 2015;385:2077-87.

84. Maguire M, Fuh L, Goldstein JN, et al. Thromboembolic Risk of 4-Factor Prothrombin Complex Concentrate versus Fresh Frozen Plasma for Urgent Warfarin Reversal in the Emergency Department. West J Emerg Med 2019;20:619-25.

85. Wanek MR, Hodges K, Persaud RA, et al. Prothrombin Complex Concentrates for Warfarin Reversal Before Heart Transplantation. Ann Thorac Surg 2019;107:1409-15.

86. Halder LC, Richardson LB, Garberich RF, et al. Time in Therapeutic Range for Left Ventricular Assist Device Patients Anticoagulated With Warfarin: A Correlation to Clinical Outcomes. ASAIO J 2017;63:37-40.

87. Martinez BK, Yik B, Tran R, et al. Meta-Analysis of Time in Therapeutic Range in Continuous-Flow Left Ventricular Assist Device Patients Receiving Warfarin. Artif Organs 2018;42:700-4.

88. Bishop MA, Streiff MB, Ensor CR, et al. Pharmacistmanaged international normalized ratio patient self-testing is associated with increased time in therapeutic range in patients with left ventricular assist devices at an academic medical center. ASAIO J 2014;60:193-8.

89. Bowman S, Weeks $P$, Chow E, et al. Implementation of pharmacist-managed anticoagulation in patients with continuous flow left ventricular assist devices. J Am Coll Clin Pharm 2019;2:623-7.

90. McDavid A, MacBrair K, Emani S, et al. Anticoagulation management following left ventricular assist device implantation is similar across all provider strategies. Interact Cardiovasc Thorac Surg 2018;26:60-5.

91. Levesque AA, Lewin AR, Rimsans J, et al. Development of Multidisciplinary Anticoagulation Management Guidelines for Patients Receiving Durable Mechanical Circulatory Support. Clin Appl Thromb Hemost 2019;25:1076029619837362.

92. Dionizovik-Dimanovski M, Levin AP, Fried J, et al. Correlation Between Home INR and Core Laboratory INR in Patients Supported with Continuous-Flow Left Ventricular Assist Devices. ASAIO J 2015;61:386-90.

93. Schettle S, Schloglhofer T, Zimpfer D, et al. International 
Analysis of LVAD Point-of-Care Versus Plasma INR: A

Multicenter Study. ASAIO J 2018;64:e161-5.

94. Pollari F, Fischlein T, Fittkau M, et al. Anticoagulation with apixaban in a patient with a left ventricular assist device and gastrointestinal bleeding: A viable alternative to warfarin? J Thorac Cardiovasc Surg 2016;151:e79-81.

95. Baronetto A, Centofanti P, Attisani M, et al. Dabigatran etexilate in a vitamin- $\mathrm{K}$ antagonist non responder patient during Heartware HVAD support. J Card Surg 2017;32:166-7.

96. Terrovitis JV, Ntalianis A, Kapelios CJ, et al. Dabigatran etexilate as second-line therapy in patients with a left ventricular assist device. Hellenic J Cardiol 2015;56:20-5.

97. Andreas M, Moayedifar R, Wieselthaler G, et al. Increased Thromboembolic Events With Dabigatran Compared With Vitamin K Antagonism in Left Ventricular Assist Device Patients: A Randomized Controlled Pilot Trial. Circ Heart Fail 2017;10:e003709.

98. Parikh VY, Parikh UM, Moctezuma-Ramirez A, et al. Factor Xa inhibitors in patients with continuous-flow left ventricular assist devices. Gen Thorac Cardiovasc Surg 2020. [Epub ahead of print].

99. Kirklin JK, Pagani FD, Goldstein DJ, et al. American Association for Thoracic Surgery/International Society for Heart and Lung Transplantation guidelines on selected topics in mechanical circulatory support. J Thorac Cardiovasc Surg 2020;159:865-96.

100. Kirklin JK, Naftel DC, Kormos RL, et al. Interagency Registry for Mechanically Assisted Circulatory Support (INTERMACS) analysis of pump thrombosis in the HeartMate II left ventricular assist device. J Heart Lung Transplant 2014;33:12-22.

101.Kirklin JK, Naftel DC, Pagani FD, et al. Pump thrombosis in the Thoratec HeartMate II device: An update analysis of the INTERMACS Registry. J Heart Lung Transplant 2015;34:1515-26.

102.Dang G, Epperla N, Muppidi V, et al. Medical Management of Pump-Related Thrombosis in Patients with Continuous-Flow Left Ventricular Assist Devices: A Systematic Review and Meta-Analysis. ASAIO J 2017;63:373-85

103. Cho SM, Moazami N, Katz S, et al. Reversal and

Cite this article as: Loyaga-Rendon RY, Kazui T, Acharya D. Antiplatelet and anticoagulation strategies for left ventricular assist devices. Ann Transl Med 2021;9(6):521. doi: 10.21037/atm20-4849
Resumption of Antithrombotic Therapy in LVADAssociated Intracranial Hemorrhage. Ann Thorac Surg 2019;108:52-8.

104. Najjar SS, Slaughter MS, Pagani FD, et al. An analysis of pump thrombus events in patients in the HeartWare ADVANCE bridge to transplant and continued access protocol trial. J Heart Lung Transplant 2014;33:23-34.

105.Wilson TJ, Stetler WR, Jr., Al-Holou WN, et al. Management of intracranial hemorrhage in patients with left ventricular assist devices. J Neurosurg 2013;118:1063-8.

106. Lai GY, Devlin PJ, Kesavabhotla K, et al. Management and outcome of intracranial hemorrhage in patients with left ventricular assist devices. J Neurosurg 2019;132:1133-9.

107. Wong JK, Chen PC, Falvey J, et al. Anticoagulation Reversal Strategies for Left Ventricular Assist Device Patients Presenting with Acute Intracranial Hemorrhage. ASAIO J 2016;62:552-7.

108. Kataria R, Jorde UP. Gastrointestinal Bleeding During Continuous-Flow Left Ventricular Assist Device Support: State of the Field. Cardiol Rev 2019;27:8-13.

109. Guha A, Eshelbrenner CL, Richards DM, et al. Gastrointestinal bleeding after continuous-flow left ventricular device implantation: review of pathophysiology and management. Methodist Debakey Cardiovasc J 2015;11:24-7.

110.Patel SR, Oh KT, Ogriki T, et al. Cessation of Continuous Flow Left Ventricular Assist Device-Related Gastrointestinal Bleeding After Heart Transplantation. ASAIO J 2018;64:191-5.

111. Schweiger M, Stepanenko A, Vierecke J, et al. Preexisting mitral valve prosthesis in patients undergoing left ventricular assist device implantation. Artif Organs 2012;36:49-53.

112. Rajapreyar I, Rame JE, Fiorilli P, et al. Pathological insights into persistent mitral regurgitation following continuous flow left ventricular assist device implantation. J Heart Lung Transplant 2020;39:184-6.

113. Roberts SM, Hovord DG, Kodavatiganti R, et al. Ventricular assist devices and non-cardiac surgery. BMC Anesthesiol 2015;15:185. 